$$
\text { Pontifícia Universidade C Católica }
$$

Antônio Márcio Tavares Thomé

Classificação e gestão de estoques de produtos de varejo: um estudo de caso

Dissertação de Mestrado

Dissertação apresentada como requisito parcial para obtenção do grau de Mestre (opção profissional) pelo Programa de Pós-Graduação em Engenharia de Produção do Departamento de Engenharia Industrial da PUC-Rio.

Orientador: Prof. Antônio Fernando de Castro Vieira

Rio de Janeiro

Março de 2009 


$$
\begin{array}{r}
\text { Pontifícia Universidade } \\
\text { Do Rio de Janeiro }
\end{array} \text { Cólica }
$$

Antônio Márcio Tavares Thomé

\title{
Classificação e gestão de estoques de produtos de varejo: um estudo de caso
}

\begin{abstract}
Dissertação apresentada, como requisito parcial para obtenção do título de Mestre (opção profissional) pelo Programa de Pós-Graduação em Engenharia de Produção do Departamento de Engenharia Industrial da PUC-Rio. Aprovada pela Comissão Examinadora abaixo assinada.
\end{abstract}

\author{
Prof. Antônio Fernando de Castro Vieira \\ Orientador \\ Departamento de Engenharia Industrial - PUC-Rio
}

Prof. Silvio Hamacher

Departamento de Engenharia Industrial - PUC-Rio

Prof. Madiagne Diallo

Departamento de Engenharia Industrial - PUC-Rio

Prof. José Eugênio Leal

Coordenador(a) Setorial do Centro Técnico Científico - PUC-Rio 
Todos os direitos reservados. É proibida a reprodução total ou parcial do trabalho sem autorização da universidade, do autor e do orientador.

\section{Antônio Márcio Tavares Thomé}

Graduou-se em Ciências Políticas pelo Instituto de Estudos Políticos de Bordeaux (Université de Bordeuax III), em 1977. Mestre em Demografia pelo Instituto de Demografia de Paris (Université de Paris I - Sorbonne - Nouvelle), em 1979. Cursou Técnicas Avançadas em Gestão Logística, curso de Pós-Graduação Lato Senso, no instituto COPPEAD/UFRJ (Coordenação de Programas de Pós-Graduação em Administração), em 2006. Consultor junto a Organismos Internacionais e Bancos de Desenvolvimento. Expositor e participante em congressos e simpósios. Coordenador de Avaliação e Estatísticas e Gestor de Operações na BEMFAM - Bem Estar Familiar no Brasil.

Ficha Catalográfica

Thomé, Antônio Márcio Tavares

Classificação e gestão de estoques de produtos de varejo : um estudo de caso / Antônio Márcio Tavares Thomé ; orientador: Antônio Fernando de Castro Vieira. - 2009.

95. ; $30 \mathrm{~cm}$

Dissertação (Mestrado em Engenharia Industrial) Pontifícia Universidade Católica do Rio de Janeiro, Rio de Janeiro, 2009.

Inclui bibliografia

1. Engenharia industrial - Teses. 2. Estoques. 3. ABC. 4. Cadeias de suprimentos. 5. Modelos. 6. Políticas. 7. Um almoxarifado. 8. $\mathrm{N}$ revendedores. I. Vieira, Antônio Fernando de Castro. II. Pontifícia Universidade Católica do Rio de Janeiro. Departamento de Engenharia Industrial. III. Título. 


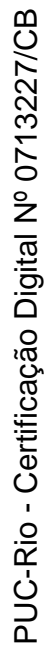

A meus pais, Jorge e Sylvia (in memoria) 


\section{Agradecimentos}

A minha esposa, Margareth, pelo incentivo e companheirismo de todas as horas.

A meus filhos, que souberam entender minhas longas horas de ausência do convívio familiar.

A meus colegas do Mestrado Profissionalizante, pelas brincadeiras, companheirismo e encorajamentos a continuar mesmo nos momentos mais difíceis.

A meu orientador, Prof. Antônio Fernando de Castro Vieira, por ter-me aceito entre seus mestrandos, por sua disponibilidade, dedicação e ensinamentos.

A todos os professores do Mestrado Profissionalizante em Logística, pelos ensinamentos e disponibilidade.

A Ney Costa, pelo companheirismo profissional de longos anos. 


\section{Resumo}

Thomé, Antônio Márcio Tavares; Vieira, Antônio Fernando de Castro (Orientador). Classificação e Gestão de Estoques de Produtos de Varejo: Um Estudo de Caso. Rio de Janeiro, 2009. 95p. Dissertação de Mestrado (Opção profissional) - Departamento de Engenharia Industrial, Pontifícia Universidade Católica do Rio de Janeiro.

Estoques ocupam um lugar central na economia e nas empresas contemporâneas. Novos paradigmas surgem na gestão de estoques, cada vez mais percebidos como elemento estratégico para a criação de valor na cadeia de suprimento. Estoques passaram a constituir um elemento chave na busca constante por vantagens competitivas entre empresas. Esta dissertação revê os principais conceitos e definições de estoques de produtos acabados. Modelos, heurísticas e políticas de estoques aplicadas a sistemas de distribuição de produtos de varejo envolvendo vários produtos, Um almoxarifado e $N$ revendedores, são definidos. Métodos de agrupamento de itens em classes ABC homogêneas são revistos e ilustrados com aplicações numéricas a produtos do ramo farmacêutico. São definidos os principais modelos e políticas de gestão de estoques adequados às diferentes classes de produtos do estudo de caso. A lógica de ressuprimentos coordenados de produtos de varejo em cadeias de suprimento de elos múltiplos é apresentada com a ajuda de exemplos. Finalmente, políticas alternativas de estoques para diferentes classes de produtos em sistemas de distribuição divergentes são apresentadas. Aspectos práticos ligados à implantação de modelos matemáticos e políticas de estoques em redes de varejo são enfatizados na conclusão do trabalho.

\section{Palavras-chave}

Estoques; ABC; Cadeias de Suprimentos; Modelos; Políticas; Um almoxarifado $-N$ revendedores 


\section{Abstract}

Thomé, Antônio Márcio Tavares; Vieira, Antônio Fernando de Castro (Advisor). Classification and Inventory Management of Retail Products: A case study. Rio de Janeiro, 2009. 95p. MSc Dissertation (Opção profissional) - Departamento de Engenharia Industrial, Pontifícia Universidade Católica do Rio de Janeiro.

Inventories are a central piece in contemporary economies and businesses. New paradigms appear in the area of inventory management, which is being increasingly perceived as a strategic element for value creation in supply chains. Inventories became a key element in the constant search for competitive advantages among companies. This dissertation reviews the main concepts and definitions of inventories as applied to finished products. Inventory models, heuristics and policies for distribution systems of retail products involving several products, One-warehouse and $N$ retailers, are defined. Methods designed to regroup items in $\mathrm{ABC}$ classes are reviewed and illustrated by numerical applications to pharmaceutical products. The main models and inventory control policies adapted to different classes of products from the case study are defined. The logic of coordinated resupply of retail products in multi-echelon supply chains is presented with examples. Finally, alternative inventory policies for different classes of products in divergent distribution systems are presented. Practical aspects related to the implementation of mathematical models and policies in retail supply chains are emphasized in the conclusion of this work.

\section{Keywords}

Inventories; ABC; Supply Chain; Models; Policies; One warehouse - $N$ retailers 


\section{Sumário}

1. Introdução 12

1.1. Justificativa 12

1.2. Objetivos 15

1.2.1. Identificar classes de itens e modelos de estoques apropriados 15

1.2.2. Descrever políticas de estoques aplicadas a um caso real 15

1.2.3. Propor políticas alternativas de gestão de estoques 16

1.3. Estrutura do trabalho 16

2. Estudo Bibliográfico 18

2.1. Definições de estoques, modelos e heurísticas 18

2.1.1. Modelos de Estoques 20

2.1.2. Heurísticas 21

2.2. Principais políticas de estoques para um só produto sob demanda $\begin{array}{ll}\text { probabilística } & 23\end{array}$

2.3. Diferentes abordagens para estoques de segurança 25

2.4. Classificação $A B C$ de estoques 27

2.4.1. Análise classificatória multicritérios 27

2.4.1.1. Método matricial de Flores e Whybark 30

2.4.1.2. Análise Hierárquica de Processos - AHP 30

2.4.1.3. Modelos de programação matemática linear ponderada 31

Método de Ramanathan 32

Método das Médias Ponderadas 33

2.4.2. Classificação de itens no interior da classe C 35

2.5. Gestão de estoques coordenados em elos múltiplos 37

2.5.1. Heurísticas para Gestão de Estoques Multi-elos 38

2.5.2. Mudanças de tempos de ciclo em cadeias multi-elos 42

3. Estudo de caso e propostas alternativas $\quad 47$

3.1. A empresa 47

3.2. A classificação dos estoques 56 
3.2.1. Situação atual 56

3.2.2. Alternativas $\quad 57$

3.3. A Gestão de Estoques 60

3.3.1. Situação Atual para produtos da Classe A-B 60

3.3.2. Alternativas para produtos da classe A-B 65

3.3.3. Situação Atual para produtos da Classe C 68

llustração Numérica $\quad 70$

3.3.4. Alternativas para produtos das classes C2 e C3 72

Ilustração numérica $\quad 74$

3.4. Ciclo do Pedido 75

3.4.1. Situação Atual 76

llustração numérica $\quad 77$

3.4.2. Alternativas ao ciclo de pedidos 78

3.5. Implantação das mudanças $\quad 79$

3.5.1. Requisitos organizacionais 80

3.5.2. Tecnologia e Auditoria da Informação 82

3.5.3. Monitoramento e Avaliação 83

4. Conclusão e perspectivas $\quad 87$

$\begin{array}{ll}\text { Referências bibliográficas } & 91\end{array}$ 


\section{Lista de figuras}

Figura 1-1. Evolução do PIB e de estoques na economia Sueca: 1980 - 200313

Figura 2-1 - Descrição e modelos matemáticos 22

Figura 2-2.- Matriz de classificação multicritérios de Flores e Whybark 29

Figura 2-3 - Papel de apoio de produtos C 37

Figura 2-4. Representações de elos na cadeia de suprimento 38

Figura 2-5. Sistema de distribuição divergente 38

Figura 3.1 - Holding $\quad 48$

Figura 3-2 -. Abrangência Geográfica $\quad 49$

Figura 3-3 - Organograma da Área de Operações $\quad 51$

Figura 3-4 - Fluxos de produtos e de informação 53

Figura 3-5. Fluxos de mercadorias para os almoxarifados regionais $\quad 54$

Figura 3-6. Sistema de controle centralizado de estoques 61

Figura 3-7. Rede logística $\quad 64$

Figura 3-8. Período de proteção numa política de tipo $(R, S)$

$\begin{array}{ll}\text { Figura 3-9 Tabela mensal de pedidos } & 76\end{array}$ 


\section{Lista de tabelas}

Tabela 1-1. Valores de estoques nos balanços patrimoniais de empresas de capital aberto no Brasil, 2008

Tabela 1-2. Comparação entre paradigmas da gestão de estoques nas empresas 14

Tabela 2-1: Tipos de políticas de estoque $\quad 24$

Tabela 2-2: Fatores para cálculo de estoques de segurança 26

Tabela 2-3 - Classificação ABC - Método de Wang Lung Ng 35

Tabela 3-1. Tempos de entrega em dias $\quad 54$

Tabela 3-2. Tempos de entrega em dias, por produtos 55

Tabela 3-3 - Classificação ABC de itens de estoque por valor médio de uso 56

Tabela 3-4 - Aplicação da classificação ABCM por médias parciais 58

Tabela 3-5 - Matriz de comparação entre classes ABC e ABCM 59

Tabela 3-6 - Metodologias de classificação e políticas de estoques 60

Tabela 3-7. Itens de estoques controlados por política de tipo $(R, s, S) \quad 69$

Tabela 3-8. Sistema de Reposição automática - Ilustração Numérica 71

Tabela 3-9. Itens de estoques controlados por política de “duas gavetas” 72

Tabela 3-10. Itens de estoques controlados pelo algoritmo de Wagner-Within 73

Tabela 3-11. Resultados do algoritmo de Wagner - Within 75

Tabela 3-12 Aplicação a dados de reposição de Anovulatórios Orais de tipo 178 